\title{
Production of recycled EPS fibers by centrifugal spinning
}

Gian Francesco dos Reis Paganotto ${ }^{1}$, Guilherme Duarte de Barros ${ }^{1}$ Viviane Göbel Marques ${ }^{1}$, Antonio Shigueaki Takimi ${ }^{2}$

\author{
${ }^{1}$ Center for Technological Development, Federal University of Pelotas, Gomes Carneiro Street, 01, CEP: 96010-610, \\ Pelotas, RS, Brazil. \\ ${ }^{2}$ Department of Metallurgy, Federal University of Rio Grande do Sul, Bento Gonçalves Avenue, 9500, CEP: 91501-970, \\ Porto Alegre, RS, Brazil. \\ e-mail: gianpaganotto@gmail.com, guilherme.engmat.ufpel@gmail.com, vivianegobelmarques@gmail.com, anto- \\ nio.takimi@gmail.com
}

\begin{abstract}
Centrifugal spinning is a new technique for producing of nano and microfibers that has a great differential: a higher production rate than those presented by traditional methods. Due to a great interest in using nano and microfibers in technological applications along with the environmental interest in polymer recycling, this research had the purpose of production fibers by centrifugal spinning from the expanded poly-styrene recycling and the evaluation of the influence of operational parameters such as the concentration of polymer solution and the speed of rotation in the average diameter and in the distribution of the diameters of fibers formed. The fibers obtained were characterized using the Scanning Electronic Microscopy (SEM) and they had their diameters measured using ImageJ software. The fibers obtained in this research were entangled, woven, fused, with a rough and porous surface, with bead formation and without directional ordering. The results obtained show that the polymer solution concentration was the most influential parameter in the fibers analyzed characteristics and, in general, its increase generates an increase in the average diameter. With the increase in rotation speed, there has been often a reduction in the presence of beads and microparticles due to the better stretching of the fibers. In less concentrated solutions, continuous fibers with more regular surfaces were obtained, however, promoting the higher production of beads. In the most concentrated solutions, we noticed the formation of porous fibers and very rough surfaces, as well as fused and woven fibers. Through the measurement of its diameters, it was possible to observe the obtaining of fibers with average diameters of $407,02 \mathrm{~nm}$ to $38113,20 \mathrm{~nm}$, and the smallest value was obtained with the parameters of $5 \% \mathrm{w} / \mathrm{w}$ of polymer concentration and rotation speed of $15000 \mathrm{rpm}$ and the highest value had $15 \% \mathrm{w} / \mathrm{w}$ concentration polymer and $10000 \mathrm{rpm}$.
\end{abstract}

Keywords: centrifugal spinning, nanofibers, microfibers, recycled expanded polystyrene.

\section{INTRODUCTION}

Population growth added to high consumerism generates a very large load of solid waste; this waste can damage the environment when there is no proper waste management at post-consumption [1-3]. One of the main concerns regarding solid waste is the disposal of polymeric materials, since these materials usually remain for a long time in the place where they were disposed [2], and in this way the recycling and reuse of these materials present itself as one of the most important actions to reduce the environmental impact [4].

According to Compromisso Empresarial para Reciclagem (Cempre) [5] - a non-profit association dedicated to the promotion of recycling - Brazil recycled in 2011 only $21.7 \%$ of plastics (approximately 953,000 tonnes), and this low percentage can be attributed to the low cost of recycled plastics and the recycling economic inviability [6]. However, recycling generates benefits such as reducing the greenhouse effect, air and water pollution, energy consumption and increasing conservation of natural resources [6].

Expanded polystyrene (EPS) is one of the polymeric materials that must have an appropriate destination and; due to its low density, EPS occupies a lot of space in the location where it is deposited. In addition, EPS is $100 \%$ recyclable and reusable [6]. Expanded polystyrene is a rigid cellular plastic, produced from the polymerization of styrene in water, with the addition of an expander agent, usually pentane [7]. The final product consists of approximately $98 \%$ air and $2 \%$ solid matter (polystyrene) in volume [8]. The closed and air-filled cells confer to EPS its properties of extreme lightness and acoustic insulation [7]. 
A proposed way to increase the demand and aggregate value to plastics is through recycling and use in the synthesis of nano and microfibers. Besides, these fibers have inherent characteristics, due to their dimensions, which result in a range of applications in several areas [9]. Polymeric nanofibers (nano, $10^{-9} \mathrm{~m}$ ) can present attractive mechanical properties for various applications, given the increased orientation of the main polymer chains along the longitudinal axis and the general increase in the material's resistance when in filament form [10].

The manufacture of polymeric nano and microfibers can be performed by several techniques such as melt blowing [11, 12], phase separation [12, 13], self-assembly [12-14], electrospinning [12, 14, 15] and centrifugal spinning [16-18]. This latest technique is a newly developed one, used for the production of nano and microfibers of fused or in solution polymers, based on the action of centrifugal pseudo-force [18]. Centrifugal spinning (or rotary jet spinning) presents a great advantage over traditional techniques such as electrospinning due to its higher production capacity, the possibility of using different polymers and low cost. Centrifugal spinning uses physical forces to produce fibers, not requiring high electric voltage [17, 19, 20$]$.

Centrifugal spinning equipment consists basically of a high-rotating motor, a fiber collection system and a rotor containing injectors and reservoir [20]. The production of fibers by centrifugal spinning can be described in three steps: jet initiation, jet extension, and solvent evaporation. In the first step, the reservoir containing the polymer solution or molten polymer rotates at a high rotation speed. When the rotation speed reaches a critical value, the hydrostatic pressure along with the pressure created by the action of centrifugal pseudo-force exceeds the capillary force, and then the solution is ejected as a jet out of the rotor through the hole $[16,21]$. In the second stage, a radial centrifugal pseudo-force directed outward extends the jet towards the collector's wall. The stretching of this jet was controlled by the balance between the viscous forces and centrifugal pseudo-force [16, 22]. Finally, the solvent evaporation occurs, dependent on the solvent diffusion through the polymer. The solvent evaporation rate depends on its volatility and, if the solvent is highly volatile, the fibers formed will be thicker, with a rapid solidification of the jet and this solidification will reduce its extension [16]; however, if the solvent evaporation is very low, a thin film can be formed by merging nonsolidified overlapping fibers on the collector [18].

Parameters such as surface tension, viscoelastic polymer properties, applied rotation, injector hole diameter, fiber collector radius, environment control (humidity and temperature), polymer solidification temperature and solvent evaporation, become extremely important regarding the control for the production of suitable fibers by centrifugal spinning [16, 18, 22, 23]. The inadequacy of the production parameters may cause defects in the fibers or even do not form fibers. In low viscosity solutions there is a lower shear rate and easier deformation, which characterizes the possible formation of thinner fibers; nevertheless, the jet elongation of the precursor solution of the fibers becomes more unstable due to the increased surface tension and it causes the formation of defects such as beads [21]. The formation of pearled structures, or beads, occurs due to their spherical structure that reduces the surface tension. In this work, was considered as bead the interruption in the elongation of the fiber and as microparticle the sphere that not belonging to fiber. The beads are usually found in fibers produced with lower viscosity solutions [18].

In this research, EPS recycled fibers were produced through the centrifugal spinning technique and we evaluated the parameters of the rotation speed and concentration of the polymer solution. The morphology and diameter of the formed fibers were investigated according to the equipment operating parameters.

\section{MATERIALS AND METHODS}

In this research, a recycled EPS was used, dissolved in chloroform (Synth, obtained commercially) at concentrations of 5\%, $10 \%$ and $15 \%$ by mass. In triplicate, the solutions were agitated for 24 hours and then characterized in a Viscometer of Brookfield brand and model LVDV-II + P at $20 \mathrm{rpm}$ with spindle 18.

The centrifugal spinning equipment used in this work was built by the group and has the configuration reported in the literature $[16,18,22]$. The parameters used initially had as a starting point studies reported in the literature $[16,18,20]$. The rotation speeds used were $5000 \mathrm{rpm}, 10000 \mathrm{rpm}$ and $15000 \mathrm{rpm}$ and these speeds were controlled by a Variac and verified using a digital tachometer. As an injector, disposable commercial hypodermic needles were used, with a diameter of $450 \mu \mathrm{m}$ defined by the manufacturer. The collector's radius used was $23 \mathrm{~cm}$.

After the production, the fibers were characterized by electronic scanning microscopy (SEM) and the purpose was to evaluate the microstructure of the fibers obtained and to observe details of the fiber formation and continuity, alignment (organization), dimensions and presence of microparticles and beads. The analyses were conducted at the Center for Southern Electron Microscopy (CEME-SUL) of the Federal University of 
Rio Grande - FURG, Rio Grande, Rio Grande de Sul, using the equipment JEOL model JSM - 6610LV. The sample were covered by a thin layer of gold, using a sputter coated with the gold target. The approximations used in the images were 1000 times, but by two simples (B1 and C3) it was necessary to use the approximation of 100 times because in this approximation was it was possible to obtain a clear image for these samples and with the population needed to measure the diameter of the fibers. An initial voltage of $10 \mathrm{KV}$ was employed to perform the analyses. In order to make measurements of the fiber diameters, a population of 50 fibers was stipulated and the software image $\mathbf{J}$ was used in the images obtained by SEM.

\section{RESULTS AND DISCUSSION}

The average viscosity and standard deviation obtained in the polymeric solutions are presented in Table 1. It was observed that the significant increase in the viscosity value occurs due to the increase of the EPS concentration in the solution. It happened because in more diluted solutions the polymeric chains are freer to move individually while in the more concentrated solutions the increase of viscosity occurs as a result of the formation of intermolecular intertwining which restricts the polymeric chain movement and leads to changes in the solution disposal properties [24].

Table 1: Results of the average and standard deviation present in the viscosity analyses.

\begin{tabular}{l|l}
\hline CONCENTRATION & VISCOSITY \\
\hline $5 \%(\mathrm{w} / \mathrm{w})$ & $11,40 \pm 0,42 \mathrm{cP}$ \\
\hline $10 \%(\mathrm{w} / \mathrm{w})$ & $55,20 \pm 0,97 \mathrm{cP}$ \\
\hline $15 \%(\mathrm{w} / \mathrm{w})$ & $567,90 \pm 1,21 \mathrm{cP}$ \\
\hline
\end{tabular}

Table 2: Nomenclature of the fibers subgroups produced in accordance with the operating parameters used and average diameters obtained of the fibers produced.

\begin{tabular}{l|l|l|l|l|l}
\hline SUBGROUP & CONCENTRATION & ROTATION & $\begin{array}{l}\text { AMOUNT } \\
\text { OF FIBERS }\end{array}$ & $\begin{array}{l}\text { AVERAGE } \\
\text { DIAMETER }\end{array}$ & $\begin{array}{l}\text { STANDARD } \\
\text { DEVIATION }\end{array}$ \\
\hline A1 & $5 \%(\mathrm{w} / \mathrm{w})$ & $5000 \mathrm{rpm}$ & 50 & $0,53 \mu \mathrm{m}$ & 0,16 \\
\hline $\mathrm{A} 2$ & $5 \%(\mathrm{w} / \mathrm{w})$ & $10000 \mathrm{rpm}$ & 50 & $0,42 \mu \mathrm{m}$ & 0,14 \\
\hline $\mathrm{A} 3$ & $5 \%(\mathrm{w} / \mathrm{w})$ & $15000 \mathrm{rpm}$ & 50 & $0,41 \mu \mathrm{m}$ & 0,13 \\
\hline $\mathrm{B} 1$ & $10 \%(\mathrm{w} / \mathrm{w})$ & $5000 \mathrm{rpm}$ & 50 & $9,46 \mu \mathrm{m}$ & 3,94 \\
\hline B2 & $10 \%(\mathrm{w} / \mathrm{w})$ & $10000 \mathrm{rpm}$ & 50 & $1,68 \mu \mathrm{m}$ & 0,84 \\
\hline B3 & $10 \%(\mathrm{w} / \mathrm{w})$ & $15000 \mathrm{rpm}$ & 50 & $1,28 \mu \mathrm{m}$ & 0,67 \\
\hline $\mathrm{C} 1$ & $15 \%(\mathrm{w} / \mathrm{w})$ & $5000 \mathrm{rpm}$ & 50 & $17,43 \mu \mathrm{m}$ & 5,40 \\
\hline $\mathrm{C} 2$ & $15 \%(\mathrm{w} / \mathrm{w})$ & $10000 \mathrm{rpm}$ & 35 & $38,11 \mu \mathrm{m}$ & 9,21 \\
\hline $\mathrm{C} 3$ & $15 \%(\mathrm{w} / \mathrm{w})$ & $15000 \mathrm{rpm}$ & 25 & $15,02 \mu \mathrm{m}$ & 11,82 \\
\hline
\end{tabular}

Table 2 contains the number of fibers that had their diameters measured, the average diameters and the standard deviation of the fiber groups produced in this research, as well as nomenclature according to the parameters evaluated. It was possible to observe a relationship between the solution viscosity and the fibers average diameter in the results obtained. According to LU et al. [21], the increase in the fiber diameter can be attributed to the increase in the solution viscosity; this escalation is related to greater intertwining and the reduction of the polymer chain mobility. This also makes difficult the chains stretching and consequently the formation of thicker fibers.

Figure 1 presents the micrographics of groups $\mathrm{A}, \mathrm{B}$ and $\mathrm{C}$ and their respective subgroups. In the A1 micrographics, the presence of fibers was observed, with continuous appearance, heterogeneous diameters, and presence of microparticles. In the image, it was still possible to observe that there is a higher concentration of microparticles than beads. In the A2 micrographics, there were entangled fibers and heterogeneous diameters. We can see that there was a smaller presence of microparticles and that these microparticles 
seemed to have smaller dimensions, however, a greater quantity of beads was observed. In the A3 micrographics, it was observed that the fibers had a continuous aspect, heterogeneous diameters; they were entangled, and it was possible to see the expressive presence of beads, and the formation of microparticles was not observed.
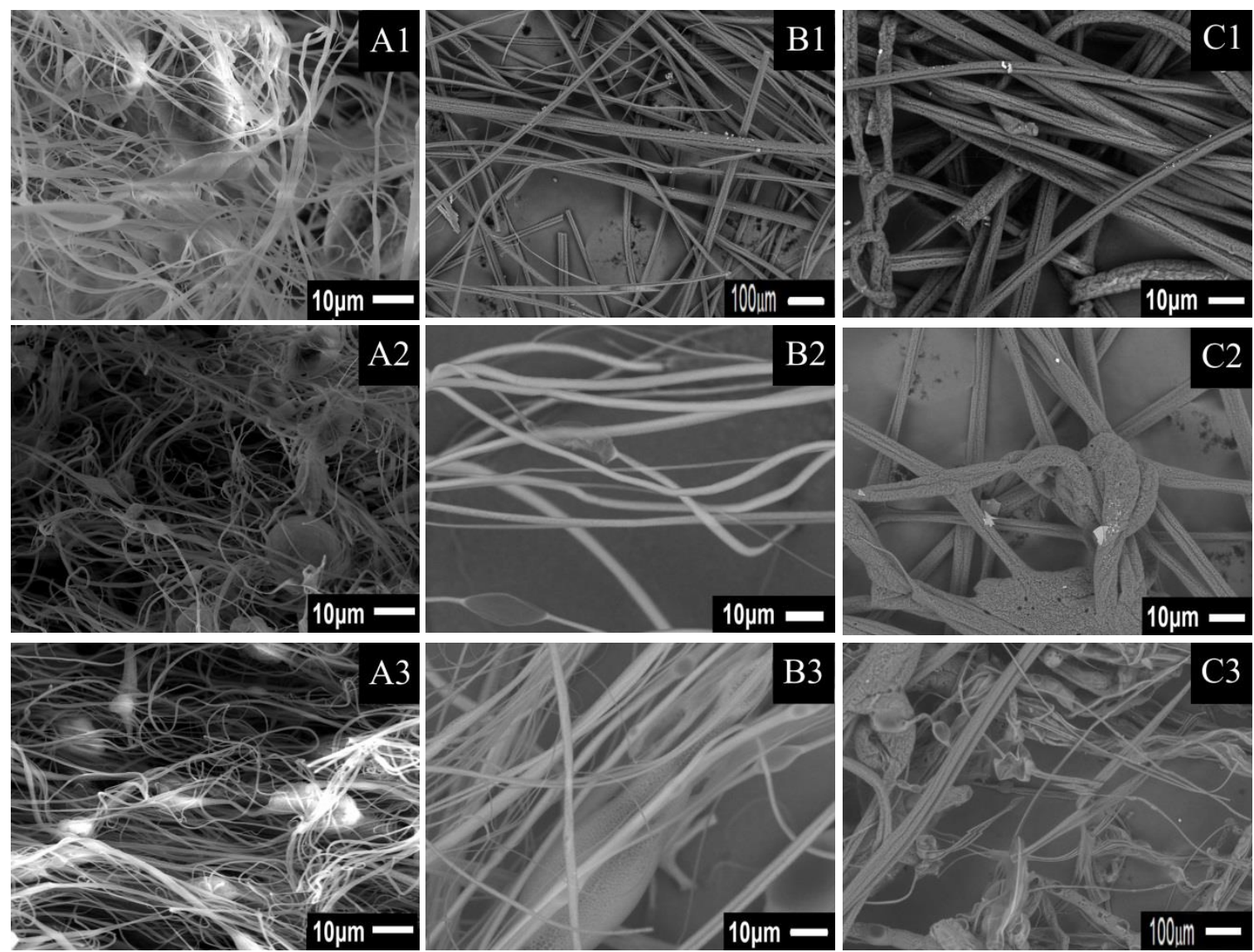

Figure 1: Micrographics obtained by SEM of the fibers of group A, group B and group C.

When considering the figures relating to group A and table 2, it was possible to observe that the increase in rotation speed has led to the formation of fibers with smaller diameters. This can be associated with a lower rotation that gives the solution jet a smaller extensional force exerted on the polymer solution jet and consequently the extension and elongation of the polymeric chains are smaller, tending to the formation of fibers with larger diameters. The trend observed for the group A is in accordance with the one observed by BADROSSAMAY et al. [16], LU et al. [21] and PADRON et al. [18].

In the micrographics of the group B the formation of fibers with distinct dimensions and different characteristics is observed, while noticing the bead formation. In the B1 micrographics, it was observed discontinuous fibers with a porous surface. It was noted that the fibers formed were coarse and these fibers demonstrated an aspect of fused fibers, which can be attributed to the combination of the use of lower rotation with a solution of greater viscosity. In the B2 micrographics, the use of a larger rotation (10000 RPM) promoted the best stretching of the polymeric chains; this stretching enabled the fiber formation with a continuous appearance as well as the presence of beads and microparticles. The B3 micrographics demonstrate the formation of fibers with a continuous aspect, with distinct dimensions among themselves, the formation of beads and microparticles.

The C1 micrographics demonstrate the formation of tangled fibers, with large diameters and porous surface, and portions containing fused fibers. In the $\mathrm{C} 2$ micrographics, it was observed the formation of short and fused fibers and these fibers form several intertwining points, these points contain a large number of pores on the surface. In the micrographics $\mathrm{C} 3$, we noted the formation of short, fused, tangled and intertwining fibers.

In general, the use of a lower rotation provided to the solution jet more time for its stretch and better 
control over the solvent evaporation. However, the extensional force exerted on the polymer solution jet was lower and consequently the extension and elongation of the polymeric chains, tending to the formation of fibers with larger diameters. When with a very high rotation, even if it can generate larger extension forces, it can cause a solvent evaporation in time not suitable for the formation of continuous fibers with good properties.

Regarding the polymer solution concentration, it was observed that in solutions of larger concentrations occurs the increase of the stretching forces, but also the decrease in the mobility of the molecules of the polymer happens due to the largest amount of polymeric chains present in the solution. This can prevent the solvent evaporation thanks to the formation of a barrier. This can be verified by observing the micrographics of the group with greater polymer concentration (group C), were the formation of very defective fibers was noted indicating that the evaporation did not occur properly.

\section{CONCLUSIONS}

Regarding the parameters evaluated in the fibers produced in this research, it was found that the concentration of the polymer solution was the most influential parameter in the variation of the diameters obtained. The fibers obtained in this research were entangled without a directional ordering. In less concentrated solutions, we noticed the formation of continuous fibers with more regular surfaces, however, with higher production of beads. In the most concentrated solutions, it was observed the formation of porous fibers and very rough surfaces, as well as fused and intertwining fibers.

\section{ACKNOWLEDGMENTS}

To CEME-SUL of FURG by the analyses conducted and to FAPERGS by the financial support.

\section{BIBLIOGRAPHY}

[1] GODECKE, M.V., NAIME, R.H., FIGUEIREDO, J.A.S., "O consumismo e a geração de resíduos sólidos urbanos no Brasil”, Revista Eletrônica em Gestão, Educação e Tecnologia Ambiental, v. 8, n. 8, pp. 1700-1712, 2012.

[2] ABUL, S., "Environmental and health impact of solid waste disposal at Mangwaneni Dumpsite in Manzini: Swaziland”, Journal of Sustainable Development in Africa, v. 12, n. 7, pp. 64-78, 2010.

[3] SANKOH, F.P., YAN, X., TRAN, Q., "Environmental and Health Impact of Solid Waste Disposal in Developing Cities: A Case Study of Granville Brook Dumpsite, Freetown, Sierra Leone", Journal of Environmental Protection, v. 4, pp. 665-670, 2013.

[4] HOPEWELL, J., DVORAK, R., KOSIOR, E., "Plastics recycling: challenges and opportunities", Philosofical Transactions of the Royal Society B, v. 364, pp. 2115-2126, 2009.

[5] ZANDER, N.E., SWEETSER, D., COLE, D.P., et al., "Formation of nanofibers from pure and mixed waste streams using electrospinning”, Industrial \& engineering chemistry research, v. 54, pp. 9057-9063, 2015.

[6] ACTON, Q.A., Styrenes-Advances in Research and Application: 2013 Edition, Atlanta, ScholarlyBrief, 2013.

[7] TAN, R.B.H., KHOO, H.H., "Life cycle assessment of EPS and CPB inserts: design considerations and end of life scenarios", Journal of Environmental Management, v. 74, pp. 195-205, 2005.

[8] PISIGNANO, D., Polymer Nanofibers: Building Blocks for Nanotechnology, Cambridge, Royal Society of Chemistry, 2013.

[9] HUANG, Z.M., ZHANG, Y.Z., KOTAKI, M., et al., “A review on polymer nanofibers by electrospinning and their applications in nanocomposites", Composites Science and Technology, v. 63, pp. 2223-2253, 2003.

[10] LIN, J., SHANG, Y., DING, B., et al., "Nanoporous polystyrene fibers for oil spill cleanup”, Marine Pollution Bulletin, v. 64, pp. 347-352, 2012.

[11] ELLISON, C.J., PHATAK, A., GILES, D.W., et al., "Melt blown nanofibers: Fiber diameter distributions and onset of fiber breakup", Polymer, v. 48, pp. 3306-3316, 2007.

[12] ZHANG, Y., LIM, C.T., RAMAKRISHNA, S., et al., "Recent development of polymer nanofibers for biomedical and biotechnological applications", Journal of materials science: materials in medicine, v. 16, pp. 933-946, 2005. 
[13] DAHLIN, R.L., KASPER, F.K., MIKOS, A.G., "Polymeric nanofibers in tissue engineering", Tissue engineering: Part B, Reviews, v. 17, n. 5, pp. 349-364, 2011.

[14] WADE, R.J., BURDICK, J.A., “ Advances in nanofibrous scaffolds for biomedical applications: From electrospinning to self-assembly”, Nano Today, v. 9, pp. 722-742, 2014.

[15] NAYAK, R., PADHYE, R., KYRATZIS, I.L., et al., "Recent advances in nanofibre fabrication techniques", Textile Research Journal, v. 82, n.2, pp. 129-147, 2012.

[16] BADROSSAMAY, M.R., MCILWEE, H.A., GOSS, J.A., et al., "Nanofiber Assembly by Rotary jetspinning", Nano Letters, v. 10, pp. 2257-2261, 2010.

[17] RAGHAVAN, B., SOTO, H., LOZANO, K., "Fabrication of Melt Spun Polypropylene Nanofibers by Forcespinning”, Journal of Engineered Fibers and Fabrics, v. 8, n. 1, pp. 52-60, 2013.

[18] PADRON, S., FUENTES, A., CARUNTU, D., et al., “ Experimental study of nanofiber production through forcespinning”, Journal of Applied Physics, v. 113, n. 2, pp. 024318, 2013.

[19] MARY, L.A., SENTHILRAM, T., SUGANYA, S., et al., "Centrifugal spun ultrafine fibrous web as a potential drug delivery vehicle”, Express Polymer Letters, v. 7, n. 3, pp. 238-248, 2013.

[20] REN, L., KOTHA, S.P., "Centrifugal jet spinning for highly efficient and large-scale fabrication of barium titanate nanofibers", Materials Letters, v. 117, pp. 153-157, 2014.

[21] LU, Y., LI, Y., ZHANG, S., et al., "Parameter study and characterization for polyacrylonitrile nanofibers fabricated via centrifugal spinning process", European Polymer Journal, v. 49, pp. 3834-3845, 2013.

[22] MELLADO, P., MCILWEE, H.A, BADROSSAMAY, M.R., et al., "A simple model for nanofiber formation by rotary jet-spinning”, Applied Physics Letters, v. 99, pp. 203107, 2011.

[23] LOORDHUSWAMY, A.M., KRISHNASWAMY, V.R., KORRAPATI, P.S., et al., "Fabrication of highly aligned fibrous scaffolds for tissue regeneration by centrifugal spinning technology", Materials science and engineering $C$, v. 42, pp. 799-807, 2014.

[24] MELLO, I.L., COUTINHO, F.M.B., DELPECH, M.C., et al., “ Polibutadieno Alto-cis: Estudo Viscosimétrico em Tolueno e Ciclo-hexano”. Polímeros: Ciência e Tecnologia, v. 16, n. 1, pp. 53-60, 2006.

[25] FANG, Y., DULANEY, A.R., GADLEY, J., et al., “A comparative parameter study: Controlling fiber diameter and diameter distribution in centrifugal spinning of photocurable monomers", Polymer, v. 88, pp. 102-111, 2016.

\section{ORCID}

Gian Francesco dos Reis Paganotto

Guilherme Duarte de Barros

Viviane Göbel Marques

Antonio Shigueaki Takimi https://orcid.org/0000-0001-9917-0330

https://orcid.org/0000-0001-8021-8875

https://orcid.org/0000-0002-8831-1932

https://orcid.org/0000-0003-4681-2293 